\title{
A recombinant antibody toolbox for Dictyostelium discoideum
}

\author{
Wanessa C. Lima*, Philippe Hammel and Pierre Cosson
}

\begin{abstract}
Objective: The amoeba Dictyostelium discoideum has been a valuable model organism to study numerous facets of eukaryotic cell biology, such as cell motility, cell adhesion, macropinocytosis and phagocytosis, host-pathogen interactions and multicellular development. However, the relative small size of the Dictyostelium community hampers the production and distribution of reagents and tools, such as antibodies, by commercial vendors.

Results: For the past 5 years, our laboratory has worked to promote an increased use of recombinant antibodies (rAbs) by academic laboratories. Here we report our efforts to ensure that Dictyostelium researchers have access to rAbs. Using hybridoma sequencing and phage display techniques, we generated a panel of recombinant antibodies against $D$. discoideum antigens, providing a useful and reliable set of reagents for labelling and characterization of proteins and subcellular compartments in D. discoideum, accessible to the entire Dictyostelium community.
\end{abstract}

Keywords: Dictyostelium discoideum, Recombinant antibodies, Sequenced antibodies, Hybridoma, Phage display

\section{Introduction}

For the past seven decades, the social amoeba Dictyostelium discoideum has been used as a model organism to elucidate the molecular mechanisms underlying numerous eukaryotic cellular processes, notably multicellular development, cell motility, chemotaxis, macropinocytosis and phagocytosis, endocytic vesicle traffic, cell adhesion, caspase-independent cell death, host-pathogen interactions, and microbial infections $[1,2]$. D. discoideum is a haploid organism, with a relatively small genome ( $34 \mathrm{Mb})$ containing around 12,000 predicted proteins. From an evolutionary perspective, $D$. discoideum diverged from the animal lineage before fungi and yeasts, but after plants. Many cellular functions, absent in plant cells, appeared at this stage, in particular cell motility, chemotaxis, phagocytosis and cell adhesion. Due to the higher rate of evolutionary changes inside the Fungi group, the evolutionary distance between Dictyostelium and human is shorter than that between human and yeast [3]. Many

*Correspondence: Wanessa.DeLima@unige.ch

Geneva Antibody Facility, Faculty of Medicine, University of Geneva, 1 rue Michel Servet, 1211 Geneva, Switzerland gene products lost in fungi are maintained in $D$. discoideum, including orthologs of human genes responsible for a variety of diseases $[1,4]$.

Despite its relevance as a model organism, the Dictyostelium scientific community is relatively small, and this can hamper the development of new tools and techniques. One of the most critical tools in cell biology research are antibodies, extensively used for detection and characterization of proteins and cellular components. The mono- and polyclonal antibodies against $D$. discoideum antigens currently in use have been mostly developed during the 1980s; due to the small size of the community, they are not commercially available [1]. Because mono- and polyclonal antibodies are finite resources, many of these anti-Dictyostelium tools are either not widely available or have already been lost forever.

This is a critical situation, and the solution is twofold. On the one hand, the existing monoclonal antibodies produced by hybridomas need to be secured by determining their aminoacid sequences. On the other hand, the past 15 years have seen an explosion of techniques and tools for discovery of recombinant 
antibodies (rAbs), notably the phage display technique. These new tools allow the community to enrich the list of rAbs against $D$. discoideum targets. Each time a laboratory engages in the sequencing of a hybridoma or in the discovery and characterization of a new recombinant antibody, it facilitates future work for the whole Dictyostelium research community.

For the past 5 years, we have used hybridoma sequencing and phage display technologies to ensure that more and more Dictyostelium researchers have access to recombinant antibodies [5]. In this study, we describe a panel of recombinant antibodies against $D$. discoideum antigens, providing a toolbox for detection, characterization and isolation of proteins and subcellular compartments in $D$. discoideum.

\section{Main text \\ Material \& methods Hybridoma sequencing}

The strategy used for hybridoma sequencing is based on the protocol by Schaefer et al. [6]. Frozen vials of hybridoma cells were thawed, resuspended in pre-warmed PBS, pelleted (2000 rpm, $4 \mathrm{~min}$ ), and resuspended in $1 \mathrm{ml}$ pre-warmed PBS. $5 \times 10^{6}$ cells were used for RNA extraction according to the manufacturer's instructions (RNeasy mini kit, Qiagen \#74104). cDNA synthesis $\left(1 \mu \mathrm{g}\right.$ RNA) was done using Superscript ${ }^{\mathrm{TM}}$ II reverse transcriptase (ThermoFisher \#18064014), and random hexamers (ThermoFisher \#SO142).

Following the cDNA synthesis reaction, the heavy $\left(\mathrm{V}_{\mathrm{H}}\right)$ and light $\left(\mathrm{V}_{\mathrm{L}}\right)$ variable domain sequences were amplified by PCR using degenerate primer sets (500 nM, Integrated DNA Technologies; Additional file 1: Table S1) using GoTaq polymerase (Promega \#M7848). PCR conditions were: $95^{\circ} \mathrm{C}$ for $90 \mathrm{~s} ; 5$ cycles of $95^{\circ} \mathrm{C}$ for $30 \mathrm{~s}, 55^{\circ} \mathrm{C}$ for $30 \mathrm{~s}, 72^{\circ} \mathrm{C}$ for $45 \mathrm{~s} ; 20$ cycles of $95^{\circ} \mathrm{C}$ for $30 \mathrm{~s}, 63^{\circ} \mathrm{C}$ for $30 \mathrm{~s}, 72^{\circ} \mathrm{C}$ for $45 \mathrm{~s} ; 72^{\circ} \mathrm{C}$ for 5 min.

The PCR products were column-purified and doubledigested with HindIII-Hf and SacII (NEB \#R3104 and \#R0157). $V_{L}$ products were additionally treated with BfuI and/or BseRI (ThermoFisher \#ER1501 and NEB \#R0581), to eliminate the myeloma aberrant light chain from the myeloma fusion partner. Digested products were gel-purified (300-400 bp) and cloned into pBSKvector (GenBank \#X52330.1, HindIII-Hf/SacII digested and dephosphorylated). 6-10 clones with the correct fragment size were sequenced to obtain the consensus sequences of the $\mathrm{V}_{\mathrm{H}}$ and $\mathrm{V}_{\mathrm{L}}$ domains; definition of the heavy and light chain boundary sequences, based on alignment with germline sequences, was done using the VBASE2 server [7].

\section{Antibody conversion into an scFv-Fc format}

A recombinant antibody can be made in several formats and flavors; our format of choice is an $\mathrm{scFv}$ (single chain Fv) linked to an Fc moiety by a small AAARS linker (Additional file 1: Fig. S1). The $\mathrm{V}_{\mathrm{H}}$ and $\mathrm{V}_{\mathrm{L}}$ sequences, joined by a peptide linker (GGGGS) ${ }_{3}$, were synthesized by Invitrogen GeneArt (ThermoFisher). The synthesized fragments were double-digested with NotI-HF and NcoIHF (NEB \#R3189 and \#R3193) and cloned into homemade expression vectors, containing the Fc moieties of mouse (IgG2A, UniProt \#P01867) or rabbit (IgG, UniProt \#P01870).

For antibody production, HEK293 suspension cells (growing in FreeStyle $^{\mathrm{TM}} 293$ Expression Medium, Gibco \#12338) were transiently transfected with the vector coding for the corresponding scFv-Fc. Supernatants were collected after 4 days, and antibody yields were assessed by Page Blue staining (ThermoFisher \#24620) against markers of known concentrations.

\section{Immunofluorescence}

$5 \times 10^{5} \mathrm{D}$. discoideum DH1 cells, grown axenically at $21{ }^{\circ} \mathrm{C}$, were allowed to settle on a $22 \times 22 \mathrm{~mm}$ glass coverslip (Menzel-Gläser) for $90 \mathrm{~min}$ at room temperature in HL5 medium, then fixed with HL5 +4\% (w/v) paraformaldehyde (Applichem \#A3013) for $30 \mathrm{~min}$, and blocked with $\mathrm{PBS}+40 \mathrm{mM}$ ammonium chloride $\left(\mathrm{NH}_{4} \mathrm{Cl}\right)$ (Applichem \#A3661) for $5 \mathrm{~min}$. Cells were then permeabilized in methanol at minus $20{ }^{\circ} \mathrm{C}$ for $2 \mathrm{~min}$, washed once with PBS (5 min), and incubated for $15 \mathrm{~min}$ in PBS $+0.2 \%(\mathrm{w} / \mathrm{v})$ BSA (PBS-BSA). Cells were then incubated for $30 \mathrm{~min}$ with the indicated scFv-Fc antibody. For co-labelling experiments, the original mouse hybridoma supernatant was added to this incubation, and the reformatted antibody exhibited a rabbit Fc. After 3 washes $(5,5,15 \mathrm{~min})$ with PBS-BSA, cells were incubated for 30 min with secondary goat anti-mouse IgG conjugated to AlexaFluor-488 and/or anti-rabbit IgG conjugated to AlexaFluor-647 (1:300, Molecular Probes \#A11029 and \#A21245). After 3 washes $(5,5,15 \mathrm{~min})$ with PBS-BSA and one wash ( $5 \mathrm{~min}$ ) with PBS, coverslips were mounted on slides (Menzel-Gläser, $76 \times 26 \mathrm{~mm}$ ) with Möwiol (Hoechst) $+2.5 \%(\mathrm{w} / \mathrm{v})$ DABCO (Fluka, \#33480). Pictures were taken using a Zeiss LSM700 confocal microscope, with a $63 \times$ Neofluar oil immersion objective.

\section{Results and discussion \\ Sequencing of monoclonal antibodies and conversion to recombinant antibodies}

The production of monoclonal antibodies by hybridoma cell lines was first achieved in 1975 [8] and was a major technological development in biomedical research. 
Despite its enormous importance, the technique is not devoid of problems, the most serious being the possibility of losing a particular hybridoma cell line-because either the cells die or they are unable to regrow. In addition, hybridoma cell lines are genetically unstable and it is not uncommon to see a cell line lose the ability to produce antibodies [9].

One easy solution is to sequence the antibody genes directly from the hybridoma cells. This guarantees a permanent, inexpensive and flexible storage, since all the information is contained in an electronic file, and/or in a DNA plasmid [10]. Once the sequence information is available, it can easily be stored and propagated, and it can also be used to produce the corresponding recombinant antibody. A recombinant antibody has the flexibility to be produced in a variety of systems (in bacteria, fungi or mammalian cells, to give only a few examples) and formats, in particular with any protein/peptide tag or Fc region (the binding site for secondary reagents)
(Additional file 1: Fig. S1). As a consequence, a mouse monoclonal antibody produced by hybridoma cells can easily be turned into a rabbit-like antibody, or decorated with affinity tags or fluorochromes (such as Myc or GFP).

In our laboratory, we have a collection of more than 70 hybridoma cell lines producing antibodies against diverse Dictyostelium antigens, created by us and others over the last 30 years (for a complete list, see Additional file 1: Table S2). Using well-established techniques of hybridoma sequencing, we determined the antibody sequence for 26 of them (Table 1). Twelve were converted to recombinant antibodies. For this, the two variable regions were fused to create a single-chain variable fragment $(\mathrm{scFv})$, which was then joined to a mouse or rabbit Fc moiety (Table 1 and Additional file 1: Fig. S1).

To characterize the converted rAbs, immunofluorescence and/or western blot experiments were performed, comparing the original IgG produced by the hybridoma

Table 1 List of sequenced hybridomas; highlighted in bolditalic, the antibodies converted to rAbs

\begin{tabular}{|c|c|c|c|c|c|c|}
\hline $\mathrm{ABCD}_{-}^{\mathrm{a}}$ & Hybridoma & UniProt & DDB_ & Target & Original ref. & rAb ref. ${ }^{b}$ \\
\hline AN700 & H9 & - & - & Membrane protein p23 & {$[11]$} & \\
\hline AJ155 & $\mathrm{H} 194$ & - & - & Membrane protein p23 & {$[11]$} & {$[12]$} \\
\hline AJ513 & $\mathrm{H} 72$ & - & - & Membrane protein p25 & {$[11]$} & {$[13]$} \\
\hline AN701 & $\mathrm{H} 36$ & - & - & Surface protein p46 & {$[14]$} & \\
\hline AJ514 & $221-342-5$ & - & - & Common antigen 1 (CA1) & {$[15]$} & {$[16,17]$} \\
\hline AN704 & $173-185-1$ & - & - & Common antigen 1 (CA1) & {$[18]$} & \\
\hline AK426 & $1 / 39$ & - & - & Golgi & {$[19]$} & {$[20]$} \\
\hline AK423 & $224-236-1$ & P07830 & several & Actin & {$[21]$} & {$[22,23]$} \\
\hline AK566 & 33-294-17 & P08796 & G0289073 & Contact site A protein & {$[24]$} & \\
\hline AN709 & $41-71-21$ & P08796 & G0289073 & Contact site A protein & {$[24]$} & \\
\hline AK425 & $176-3-6$ & P27133 & G0267382 & Coronin A & {$[25]$} & \\
\hline AN706 & $194-62-7$ & P27133 & G0267382 & Coronin A & {$[26]$} & \\
\hline AN707 & $130-80-2$ & P21837 & G0285419 & Crystal protein & {$[27]$} & \\
\hline AN710 & $80-52-13$ & P02886 & G0273063 & Discoidin 1 chain A & {$[28]$} & \\
\hline AJ154 & $\mathrm{H} 161$ & Q7YXD4 & G0287297 & Endosomal membrane protein p80 & {$[11]$} & {$[29,30]$} \\
\hline AN702 & H191 & Q7YXD4 & G0287297 & Endosomal membrane protein p80 & {$[11]$} & \\
\hline AK421 & $70-100-1$ & Q01501 & G0271848 & Porin A & {$[31]$} & {$[32,33]$} \\
\hline AK424 & $21-55-4$ & P08799 & G0286355 & Myosin II heavy chain & {$[34]$} & \\
\hline AN708 & $21-96-3$ & P08799 & G0286355 & Myosin II heavy chain & {$[35]$} & \\
\hline AK567 & $221-64-1$ & Q86IA3 & G0276141 & Protein disulfide isomerase & {$[36]$} & $c$ \\
\hline AN703 & $221-42-1$ & Q86IA3 & G0276141 & Protein disulfide isomerase & {$[36]$} & \\
\hline AK422 & B4.2 & 077257 & G0278725 & Secreted protein SctA & {$[37]$} & {$[38]$} \\
\hline AJ156 & $169-477-5$ & P0CE95 & G0290481 & Talin A & {$[39]$} & {$[40,41]$} \\
\hline AN705 & $227-341-4$ & P0CE95 & G0290481 & Talin A & {$[42]$} & \\
\hline AJ520 & $221-35-2$ & P54647 & G0287127 & V-ATPase subunit A & {$[43]$} & {$[44,45]$} \\
\hline AJ515 & $224-256-2$ & P54648 & G0284473 & V-ATPase subunit C & [46] & $c$ \\
\hline
\end{tabular}

a $A B C D$ nomenclature (https://web.expasy.org/abcd/); the ABCD database is a manually curated repository of sequenced antibodies [47]

b "Original references" correspond to the first descriptions of a monoclonal antibody. "rAb references" describe the characterization of the converted rAbs

c The recombinant versions of these antibodies were not produced efficiently in our hands 


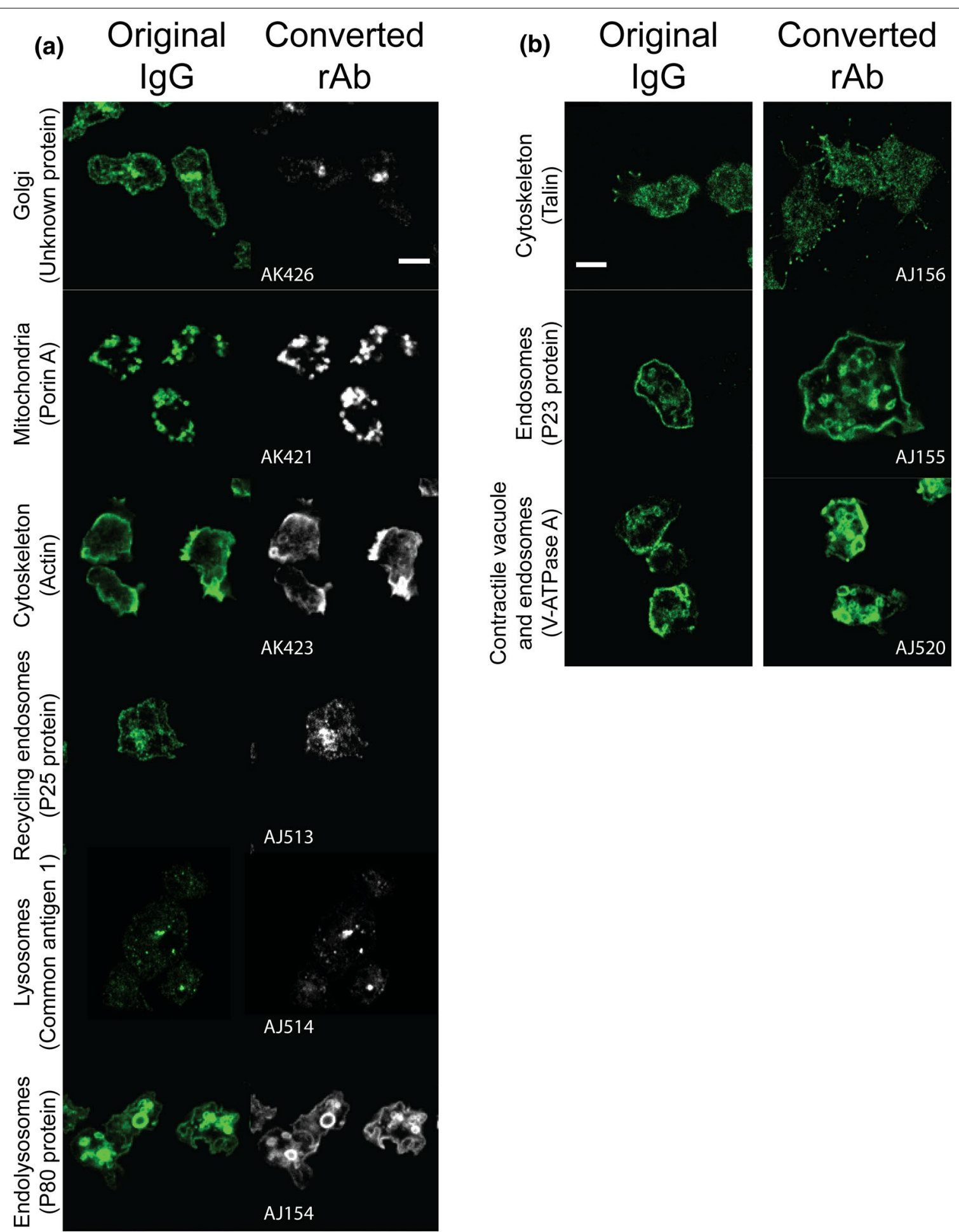

Fig. 1 A panel of recombinant antibodies labels specific Dictyostelium subcellular compartments. The target antigen is indicated between parentheses. In (a), double immunolabelling with the original mouse lgG and the converted rAb (with a rabbit Fc) shows the same staining pattern. In (b), the converted $\mathrm{rAb}$ has a mouse $\mathrm{Fc}$, and double immunolabelling could not be performed; staining patterns are identical. For more images and experimental details, please refer to the rAb references indicated in Table 1 
Table 2 List of recombinant antibodies discovered by phage display

\begin{tabular}{|c|c|c|c|c|}
\hline $\mathrm{ABCD}$ & UniProt & DDB & Target & Refs. \\
\hline RB339-342 & Q86B07 & G0272785 & Acyloxyacyl hydrolase AoaH & \\
\hline RB152-154, RB186-188 & Q8T7K0 & G0275451 & ALG-2 interacting protein $X$ & \\
\hline RB393-395 & Q54Q68 & G0284043 & Amoebapore-like protein AplA & \\
\hline RB349-357 & Q54LG3 & G0286651 & Amoebapore-like protein AplB & \\
\hline RB358-363 & Q54SX7 & G0282153 & Amoebapore-like protein AplH & \\
\hline RB345-348 & Q54JE8 & G0288095 & Bactericidal permeability-increasing protein BpiA & \\
\hline RB364-386 & Q55BA2 & G0271242 & Bactericidal permeability-increasing protein BpiC & \\
\hline RB169-178 & P34090 & G0275007 & Conditioned medium factor CmfA & \\
\hline RB155-156, RB189 & Q54LJ3 & G0286797 & ESCRT-I complex subunit Tsg101 & {$[55]$} \\
\hline RB337-338 & Q54DN3 & G0291986 & Exportin-7 & \\
\hline RB167-168 & Q54U89 & G0281211 & Folate receptor Far1 & {$[51]$} \\
\hline RB002, RB004-005, RB009, RB045, RB048 & Q54KF7 & G0287363 & Integrin beta-like protein SibA & {$[50]$} \\
\hline RB097, RB103 & Q54TM7 & G0281557 & Leucine-rich repeat kinase LrrkA & \\
\hline RB305-306 & Q9XYS8 & G0267406 & Lysosome membrane protein 2-A & \\
\hline RB313-318 & Q9BKJ9 & G0287035 & Lysosome membrane protein 2-B & \\
\hline RB328-331 & Q55FQ9 & G0267440 & Lysosome membrane protein 2-C & \\
\hline RB343-344, RB376-378, RB464-467 & Q8T1G4 & G0275123 & Lysozyme AlyA & {$[53,56,57]$} \\
\hline RB388-392, RB447-453 & Q54M35 & G0286229 & Lysozyme AlyL & {$[54,58-60]$} \\
\hline RB320-327, RB396-399 & Q55GK8 & G0267630 & Membrane-associated sulfotransferase Kil1 & \\
\hline RB007, RB011-012 & Q54EY0 & G0291275 & Mucolipin & {$[50]$} \\
\hline RB285-290 & Q867T7 & G0288773 & NADPH oxidase activator NcfA & {$[61]$} \\
\hline RB436-442 & Q54KA3 & G0287497 & Nucleoporin 133 & {$[62,63]$} \\
\hline RB003, RB015-016 & Q55FP0 & G0267444 & Phagocytic receptor $1 a$ & {$[50]$} \\
\hline RB332-336 & Q54ZW0 & G0277273 & Phagocytic receptor $1 \mathrm{~b}$ & \\
\hline RB291-293 & Q553Q2 & G0275345 & Rab GTPase-activating protein 1-like & \\
\hline RB431-435 & P18613 & G0291237 & Rap GTPase RapA & {$[64]$} \\
\hline RB001 & Q9NIV0 & G0283389 & Rhesus-like glycoprotein A & \\
\hline RB374-375 & Q54N92 & G0285435 & RNB domain-containing ribonuclease & \\
\hline RB179-182 & Q54H46 & G0289791 & Serine/threonine-protein kinase DrkA & \\
\hline RB019-021 & Q54JQ7 & G0287845 & Spreading and phagocytosis regulator SpdA & {$[52]$} \\
\hline RB008 & Q9XYS3 & G0289653 & Superoxide-generating NADPH oxidase heavy chain subunit A & \\
\hline RB010, RB039-040, RB042 & Q86GL4 & G0287101 & Superoxide-generating NADPH oxidase heavy chain subunit B & \\
\hline RB025-026 & Q54F44 & G0291117 & Superoxide-generating NADPH oxidase heavy chain subunit $C$ & {$[50]$} \\
\hline RB029-031, RB060-062 & Q55CW7 & G0269872 & Tetraspanin TspB & \\
\hline RB513-518 & - & - & Unknown lysosomal protein & {$[65]$} \\
\hline RB098-102 & Q54KX3 & G0287055 & Vacuolar protein sorting-associated protein $13 \mathrm{~F}$ & \\
\hline RB150-151, RB183-185 & Q54PT2 & G0284347 & Vacuolar protein sorting-associated protein 4 & \\
\hline RB256-267 & 015706 & G0289485 & Vacuolin A & \\
\hline RB268-269 & - & - & Vacuolin ABC & \\
\hline RB258-259 & Q54WZ2 & G0279191 & Vacuolin B & \\
\hline RB260-261 & Q54WZ3 & G0279307 & Vacuolin C & \\
\hline
\end{tabular}

cells and the derived rAb. Ten of the converted rAbs recapitulated the immunolabelling of the original antibody (Table 1 for references). In two cases (AK567 and AJ515), the converted rAbs had production yields too low to be usable and thus failed to generate a specific labeling.
This work yielded recombinant antibodies that can be used as markers of Dictyostelium subcellular compartments, notably mitochondria (AK421), Golgi apparatus (AK426), endolysosomal compartments (AJ154, AJ155, AJ513, AJ514, AJ520), cytoskeleton (AK423, AJ156), and contractile vacuole (AJ520) (Fig. 1). 


\section{Selection of new recombinant antibodies by phage display}

Strategies to select antibodies using completely in vitro methodologies first appeared in the mid-1980s [48]. However, most academic laboratories do not have access to the phage display technology for discovery of new antibodies. Since 2013, the Geneva Antibody Facility selects, produces and characterizes recombinant antibodies for the academic community, in an open-access, not-for-profit and collaborative spirit [5].

Over the past years, we have selected 184 antibodies against 41 different $D$. discoideum proteins (Table 2) using the phage display technique. The in vitro selection has been done with a wide variety of antigen molecules, including small peptides, protein domains or fragments attached to a GST carrier, full-length proteins, and even subcellular compartments and cells. All antibodies (using the already mentioned $\mathrm{scFv}$-Fc format) specifically recognize the target used for phage display discovery (a peptide, a protein fragment, a full protein) by ELISA. It should however be emphasized that an antibody directed against a peptide may fail to recognize the corresponding sequence in the full folded protein. We did not characterize in depth all the antibodies discovered; further characterization should be performed and reported by the end-user scientists themselves. We strongly encourage them to publish positive as well as negative results [5]. The recognition of an epitope by an antibody is heavily influenced by the folding state of the protein; proteins are mostly folded in ELISA or immunofluorescence experiments and largely denatured in western blot or immunohistochemistry. Consequently, antibodies that perform well with one technique often perform poorly in others [49]. It is thus of paramount importance to determine the performance of each antibody in different contexts and for different techniques.

So far, antibodies to 9 targets have been described in a scientific publication, using an additional technique to ELISA, such as western blot (Table 2). Some antibodies recognize the full-length endogenous protein (SibA, Phg1a, Far1 [50, 51]), others only recognize the fulllength protein when over-expressed (AlyA, AlyL, SpdA [52-54]), and others fail completely to recognize the fulllength protein, overexpressed or endogenous (Tsg101 [55]).

\section{Conclusions}

Given the relatively small size of the Dictyostelium scientific community, the majority of the tools and reagents are developed by the researchers themselves, and not commercially available. This is notably the case for antibodies. In addition, almost the totality of these reagents are polyclonal antibodies produced by immunizing rabbits, or monoclonal antibodies produced by mouse hybridoma cells. While polyclonal antibodies are ill-characterized reagents that should be completely phased out, monoclonal antibodies can be irretrievably lost. Since 2015, many key opinion leader scientists have published calls to employ only recombinant antibodies $[9,66]$.

Here, we describe the efforts of the Geneva Antibody Facility to develop recombinant antibodies against a panel of Dictyostelium targets, either by sequencing existing hybridoma cell lines, or by developing new antibodies using the phage display technique. We hope that these efforts will facilitate work and increase reproducibility in this scientific community. We further hope that it will encourage others to take part in this common enterprise by (i) sequencing their own hybridomas and depositing the sequences in the ABCD database (https://web.expas y.org/abcd/; [47]); (ii) selecting and characterizing antibodies to new Dictyostelium proteins; and (iii) publishing the results obtained with these antibodies.

\section{Limitations}

Antibodies developed by us are not always characterized in depth, as this is out of the scope of our laboratory. We strongly urge the end-user scientists themselves to characterize and publish any positive and/or negative results, to determine the antibody efficacy in different contexts and with different techniques.

\section{Supplementary information}

Supplementary information accompanies this paper at https://doi. org/10.1186/s13104-020-05048-8.

\begin{abstract}
Additional file 1: Fig S1. Schematic representation of the conversion of an lgG into an scFv-Fc. (A) An lgG is composed of 4 chains: 2 heavy $(H)$ and 2 light $(L)$ chains, made of a constant $(C)$ and a variable $(V)$ domain. The $F_{V}$ (variable fragment) consists of two chains $\left(V_{H}\right.$ and $\left.V_{L}\right)$ and is the region responsible for antigen recognition and binding; thus, it is the region of interest for sequencing. (B) An scFv is made of the $V_{H}$ and $V_{L}$ variable chains joined by a peptide linker (GGGGSGGGGSGGGGS). (C) An scFv-FC is an sCFv molecule fused to an Fc region; the Fc can be of any desired species (rabbit, mouse, human, guinea pig), and it is the region where secondary reagents bind to. Table S1. List of degenerate primers used for hybridoma sequencing. Table S2. Collection of Cosson lab's hybridoma cell lines producing antibodies against Dictyostelium antigens.
\end{abstract}

Abbreviations

rAb: Recombinant antibody; scFv: Single-chain variable fragment.

Acknowledgements

We are particularly grateful to Prof. Günther Gerisch (Max-Planck Institut für Biochemie, Martinsried) for the gift of multiple hybridoma cell lines.

Authors' contributions

WCL and PC conceived and coordinated the study. WCL and PH collected data and performed experiments. WCL and PC analyzed the data and wrote the manuscript. All authors read and approved the final manuscript. 


\section{Funding}

This work was funded by the ProCare Foundation and by the University of Geneva. The funding bodies had no role in the design of the study and collection, analysis, and interpretation of data.

\section{Availability of data and materials}

All data generated or analyzed during this study are included in this published article and its supplementary information files. All antibodies are available at the Geneva Antibody Facility (https://www.unige.ch/medecine/antibodies/).

\section{Ethics approval and consent to participate}

Not applicable.

\section{Consent for publication}

Not applicable.

\section{Competing interests}

The authors declare that they have no competing interests.

Received: 4 March 2020 Accepted: 28 March 2020

Published online: 10 April 2020

\section{References}

1. Bozzaro S. The model organism Dictyostelium discoideum. Methods $\mathrm{Mol}$ Biol. 2013;983:17-37.

2. Escalante R, Cardenal-Munoz E. The Dictyostelium discoideum model system. Int J Dev Biol. 2019;63:317-20.

3. Insall R. The Dictyostelium genome: the private life of a social model revealed? Genome Biol. 2005:6:222.

4. Eichinger L, Pachebat JA, Glockner G, Rajandream MA, Sucgang R, Berriman $\mathrm{M}$, et al. The genome of the social amoeba Dictyostelium discoideum. Nature. 2005;435:43-57.

5. Cosson P, Hartley O. Recombinant antibodies for academia: a practical approach. Chimia (Aarau). 2016;70:893-7.

6. Schaefer JV, Honegger A, Plückthun A. Construction of scFv fragments from hybridoma or spleen cells by PCR assembly. Antibody engineerin. Springer: Berlin; 2010. p. 21-44.

7. Retter I, Althaus HH, Munch R, Muller W. VBASE2, an integrative V gene database. Nucleic Acids Res. 2005;33:D671-4

8. Kohler G, Milstein C. Continuous cultures of fused cells secreting antibody of predefined specificity. Nature. 1975;256:495-7.

9. Bradbury A, Pluckthun A. Reproducibility: standardize antibodies used in research. Nature. 2015;518:27-9.

10. Andrews NP, Boeckman JX, Manning CF, Nguyen JT, Bechtold H, Dumitras $C$, et al. A toolbox of IgG subclass-switched recombinant monoclonal antibodies for enhanced multiplex immunolabeling of brain. Elife. 2019;8:e43322.

11. Ravanel K, de Chassey B, Cornillon S, Benghezal M, Zulianello L, Gebbie $L$, et al. Membrane sorting in the endocytic and phagocytic pathway of Dictyostelium discoideum. Eur J Cell Biol. 2001;80:754-64.

12. Lima WC, Cosson P. The AJ155 antibody recognizes the Dictyostelium p23 marker by immunofluorescence. Antib Rep. 2019;2:e43.

13. Lima WC, Cosson P. The AJ513 antibody recognizes the Dictyostelium p25 marker by immunofluorescence. Antib Rep. 2019;2:e44.

14. Mercanti V, Charette SJ, Bennett N, Ryckewaert JJ, Letourneur F, Cosson P. Selective membrane exclusion in phagocytic and macropinocytic cups. J Cell Sci. 2006;119:4079-87.

15. Knecht DA, Dimond RL, Wheeler S, Loomis WF. Antigenic determinants shared by lysosomal proteins of Dictyostelium discoideum. Characterization using monoclonal antibodies and isolation of mutations affecting the determinant. J Biol Chem. 1984;259:10633-40.

16. Pillonel C, Hammel P, Guilhen C. The AJ514 antibody recognizes the common antigen 1 from Dictyostelium discoideum by western blot. Antib Rep. 2019;2:e49.

17. Lima WC, Cosson P. The AJ514 antibody recognizes the common antigen 1 from Dictyostelium discoideum by immunofluorescence. Antib Rep. 2019;2:e45.

18. Schopohl D, Muller-Taubenberger A, Orthen B, Hess H, Reutter W. Purification and properties of a secreted and developmentally regulated
alpha-L-fucosidase from Dictyostelium discoideum. J Biol Chem. 1992;267:2400-5.

19. Graf R, Daunderer C, Schliwa M. Cell cycle-dependent localization of monoclonal antibodies raised against isolated Dictyostelium centrosomes. Biol Cell. 1999;91:471-7.

20. Lima WC. The AK426 antibody recognizes the Golgi apparatus in Dictyostelium cells by immunofluorescence. Antib Rep. 2019;2:e59.

21. Hanakam F, Albrecht R, Eckerskorn C, Matzner M, Gerisch G. Myristoylated and non-myristoylated forms of the $\mathrm{pH}$ sensor protein hisactophilin II: intracellular shuttling to plasma membrane and nucleus monitored in real time by a fusion with green fluorescent protein. EMBO J. 1996;15:2935-43.

22. Lima WC. The AK423 antibody recognizes Dictyostelium actin by western blot. Antib Rep. 2019;2:e55.

23. Lima WC. The AK423 antibody recognizes Dictyostelium actin network by immunofluorescence. Antib Rep. 2019;2:e54.

24. Bertholdt G, Stadler J, Bozzaro S, Fichtner B, Gerisch G. Carbohydrate and other epitopes of the contact site A glycoprotein of Dictyostelium discoideum as characterized by monoclonal antibodies. Cell Differ. 1985:16:187-202

25. de Hostos EL, Rehfuess C, Bradtke B, Waddell DR, Albrecht R, Murphy J, et al. Dictyostelium mutants lacking the cytoskeletal protein coronin are defective in cytokinesis and cell motility. J Cell Biol. 1993;120:163-73.

26. Faix J, Dittrich W, Prassler J, Westphal M, Gerisch G. pDcsA vectors for strictly regulated protein synthesis during early development of Dictyostelium discoideum. Plasmid. 1995;34:148-51.

27. Bomblies L, Biegelmann E, Doring V, Gerisch G, Krafft-Czepa H, Noegel AA, et al. Membrane-enclosed crystals in Dictyostelium discoideum cells, consisting of developmentally regulated proteins with sequence similarities to known esterases. J Cell Biol. 1990;110:669-79.

28. Wetterauer B, Jacobsen G, Morandini P, MacWilliams H. Mutants of Dictyostelium discoideum with defects in the regulation of discoidin I expression. Dev Biol. 1993;159:184-95.

29. Lima WC, Cosson P. The AJ154 antibody recognizes the Dictyostelium p80 protein by immunofluorescence. Antib Rep. 2019;2:e24.

30. Lima WC, Cosson P. The AJ154 antibody recognizes the Dictyostelium p80 protein by western blot. Antib Rep. 2019;2:e23.

31. Troll H, Malchow D, Muller-Taubenberger A, Humbel B, Lottspeich F, Ecke $M$, et al. Purification, functional characterization, and CDNA sequencing of mitochondrial porin from Dictyostelium discoideum. J Biol Chem. 1992;267:21072-9.

32. Lima WC. The AK421 antibody recognizes the Dictyostelium mitochondrial porin by western blot. Antib Rep. 2019;2:e57.

33. Lima WC. The AK421 antibody recognizes the Dictyostelium mitochondrial porin by immunofluorescence. Antib Rep. 2019;2:e56.

34. Pagh K, Gerisch G. Monoclonal antibodies binding to the tail of Dictyostelium discoideum myosin: their effects on antiparallel and parallel assembly and actin-activated ATPase activity. J Cell Biol. 1986;103:1527-38.

35. Claviez M, Pagh K, Maruta H, Baltes W, Fisher P, Gerisch G. Electron microscopic mapping of monoclonal antibodies on the tail region of Dictyostelium myosin. EMBO J. 1982;1:1017-22.

36. Monnat J, Hacker U, Geissler H, Rauchenberger R, Neuhaus EM, Maniak M, et al. Dictyostelium discoideum protein disulfide isomerase, an endoplasmic reticulum resident enzyme lacking a KDEL-type retrieval signal. FEBS Lett. 1997;418:357-62.

37. Sabra A, Leiba J, Mas L, Louwagie M, Coute Y, Journet A, et al. Pycnosomes: condensed endosomal structures secreted by Dictyostelium amoebae. PLoS ONE. 2016;11:e0154875.

38. Lima WC. The AK422 antibody recognizes Dictyostelium SctA protein by western blot. Antib Rep. 2019;2:e58.

39. Kreitmeier M, Gerisch G, Heizer C, Muller-Taubenberger A. A talin homologue of Dictyostelium rapidly assembles at the leading edge of cells in response to chemoattractant. J Cell Biol. 1995;129:179-88.

40. Lima WC. The AJ156 antibody recognizes the Dictyostelium Talin A protein by immunofluorescence. Antib Rep. 2019;2:e51.

41. Lima WC. The AJ156 antibody recognizes the Dictyostelium Talin A protein by western blot. Antib Rep. 2019;2:e50.

42. Niewohner J, Weber I, Maniak M, Muller-Taubenberger A, Gerisch G. Talinnull cells of Dictyostelium are strongly defective in adhesion to particle and substrate surfaces and slightly impaired in cytokinesis. J Cell Biol. 1997;138:349-61. 
43. Neuhaus EM, Horstmann H, Almers W, Maniak M, Soldati T. Ethane-freezing/methanol-fixation of cell monolayers: a procedure for improved preservation of structure and antigenicity for light and electron microscopies. J Struct Biol. 1998;121:326-42.

44. Guilhen C, Lima WC. The AJ520 antibody recognizes the Dictyostelium vacuolar H+-ATPase subunit A by western blot. Antib Rep. 2019;2:e47.

45. Lima WC, Cosson P. The AJ520 antibody recognizes the Dictyostelium vacuolar H+-ATPase subunit A by immunofluorescence. Antib Rep. 2019;2:e46.

46. Journet A, Chapel A, Jehan S, Adessi C, Freeze H, Klein G, et al. Characterization of Dictyostelium discoideum cathepsin D. J Cell Sci. 1999;112(Pt 21):3833-43.

47. Lima WC, Gasteiger E, Marcatili P, Duek P, Bairoch A, Cosson P. The ABCD database: a repository for chemically defined antibodies. Nucleic Acids Res. 2020;48:D261-4.

48. Parmley SF, Smith GP. Antibody-selectable filamentous fd phage vectors: affinity purification of target genes. Gene. 1988;73:305-18.

49. Uhlen M, Bandrowski A, Carr S, Edwards A, Ellenberg J, Lundberg E, et al. A proposal for validation of antibodies. Nat Methods. 2016;13:823-7.

50. Blanc C, Zufferey M, Cosson P. Use of in vivo biotinylated GST fusion proteins to select recombinant antibodies. Altex. 2014;31:37-42.

51. Leiba J, Sabra A, Bodinier R, Marchetti A, Lima WC, Melotti A, et al. Vps13F links bacterial recognition and intracellular killing in Dictyostelium. Cell Microbiol. 2017;19:e12722.

52. Dias M, Brochetta C, Marchetti A, Bodinier R, Bruckert F, Cosson P. Role of SpdA in cell spreading and phagocytosis in Dictyostelium. PLOS ONE. 2016;11:e0160376.

53. Lamrabet O. RB376 and RB377 antibodies recognize the Dictyostelium AlyA protein by western blot. Antib Rep. 2019;2:e10.

54. Lamrabet O, Jauslin T. RB447, RB448, RB449, RB450, RB451 and RB453 antibodies recognize a Dictyostelium AlyL protein by western blot. Antib Rep. 2018;1:e2.

55. Leuba F, Soldati T. RB155, RB156 and RB189 antibodies do not recognize the D. discoideum Tsg101 protein by western blot. Antib Rep. 2019;2:e109.
56. Lamrabet O. RB464, RB465, RB466 and RB467 antibodies do not recognize the Dictyostelium AlyA protein by western blot. Antib Rep. 2019;2:e9.

57. Hammel P, Lamrabet O. RB464, RB465, RB466 and RB467 antibodies recognize a Dictyostelium AlyA peptide by ELISA. Antib Rep. 2019;2:e19.

58. Hammel P, Jauslin T, Lamrabet O. RB388, RB389, RB390, RB391 and RB392 antibodies recognize a Dictyostelium AlyL peptide by ELISA. Antib Rep. 2019;2:e20.

59. Hammel P, Lamrabet $O$, Jauslin T. RB447, RB452 and RB453 antibodies recognize a Dictyostelium AlyL protein by ELISA. Antib Rep. 2019:2:e21.

60. Jauslin T, Lamrabet O. RB388, RB389, RB390, RB391 and RB392 antibodies do not recognize a Dictyostelium AlyL protein by western blot. Antib Rep. 2018;1:e3.

61. Hammel P, Lima WC. RB285, RB286, RB287, RB288, RB289 and RB290 antibodies recognize a Dictyostelium NcfA peptide by ELISA. Antib Rep. 2018;1:e4.

62. Hammel P, Lima WC. RB436, RB437 and RB439 antibodies recognize a Dictyostelium Nup133 peptide by ELISA. Antib Rep. 2019;2:e13.

63. Hammel P, Lima WC. RB438, RB440, RB441 and RB442 antibodies recognize a Dictyostelium Nup133 peptide by ELISA. Antib Rep. 2019;2:e14.

64. Hammel P, Lima WC. RB431, RB432, RB433, RB434, and RB435 antibodies recognize a Dictyostelium RapA peptide by ELISA. Antib Rep. 2019;2:e12.

65. Hammel P, Guilhen C. RB513, RB514, RB515, RB516, RB517 and RB518 antibodies recognize putative lysosomal proteins from Dictyostelium discoideum by ELISA. Antib Rep. 2019;2:e41.

66. Bradbury AR, Pluckthun A. Getting to reproducible antibodies: the rationale for sequenced recombinant characterized reagents. Protein Eng Des Sel. 2015;28:303-5.

\section{Publisher's Note}

Springer Nature remains neutral with regard to jurisdictional claims in published maps and institutional affiliations.
Ready to submit your research? Choose BMC and benefit from:

- fast, convenient online submission

- thorough peer review by experienced researchers in your field

- rapid publication on acceptance

- support for research data, including large and complex data types

- gold Open Access which fosters wider collaboration and increased citations

- maximum visibility for your research: over 100M website views per year

At BMC, research is always in progress.

Learn more biomedcentral.com/submissions 